Voting when Money and Morals Conflict An Experimental Test of Expressive Voting Jean-Robert Tyran

A pril 2002 D iscussion paper no. 2002-07 
Editor:

Publisher:

Electronic Publication:
Prof. Jörg Baumberger

University of St. G allen

Department of Economics

Bodanstr. 1

CH-9000 St. Gallen

Phone ++41712242241

Fax ++41712242885

Email_joerg.baumberger@unisg.ch

Forschungsgemeinschaft für $\mathrm{N}$ ationalökonomie an der U niversität St. Gallen

Dufourstrasse 48

$\mathrm{CH}-9000$ St. Gallen

Phone $\quad++41712242300$

Fax $\quad++41712242646$

www.fgn.unisg.ch/public/public.htm 


\section{Voting when Money and Morals Conflict \\ An Experimental Test of Expressive Voting}

Jean-Robert Tyran ${ }^{1}$

Author's address:

Dr. Jean-Robert Tyran

Department of Economics

Bodanstrasse 1

CH-9000 St. Gallen

Tel. $\quad$ +41712242315

Fax +41712242885

Email Jean-Robert.Tyran@ unisg.ch

\footnotetext{
${ }^{1}$ I thank Rupert Sausgruber who generously supported me in conducting experiments in Innsbruck. Roger Baumann, Urs Heiniger, Frederike Hesse, Denis Patzschke and Christian Rusch provided valuable research assistance in St. Gallen. I am grateful for comments by Simon Gächter, Louis Putterman and Frans van W inden. Helpful comments of participants at a seminar at the U niversity of Zürich, the ESA (N ew Y ork), and IAREP (Vienna) are acknowledged. I am grateful for financial support by the Zaugg foundation for basic research under project no. B11162107. I also thank the people at the Department of Economics at the London School of Economics for their hospitality.
} 


\section{Abstract}

Moral considerations may matter much in voting because the costs of expressing support for a morally worthy cause may be low in a referendum. These costs depend on whether a voter expects to affect the outcome of the referendum. To test the low-cost theory of expressive voting, we experimentally investigate a proposal to tax everyone and donate tax revenues. The analysis of expectations and voting decisions shows that expressive voting is common. However, the low-cost theory fails to explain voting decisions. Instead of affecting the costs of expressive voting, expectations appear to affect its benefits.

\section{Keywords}

Expressive voting, low-cost theory, laboratory experiments.

\section{JEL Classification}

A 13, C 9, D 72. 


\section{Introduction}

"Let me predict the outcome of the systematic and comprehensive testing of behavior in situations where self-interest and ethical values with wide verbal allegiance are in conflict. Much of the time, most of the time in fact, self-interest theory ... will win". George Stigler's (1981: 176) view that motives other than material self-interest must "most of the time" remain relatively unimportant for economic and societal outcomes is still common among economists today. The view owes its intuitive appeal to observable outcomes in competitive markets. In fact, an impressive body of evidence has accumulated showing that competitive experimental markets conform very much to the predictions of standard economics (e.g., Davis and Holt 1993: Ch. 3). However, in contrast to Stigler's prediction, motives other than material selfinterest may matter much for societal outcomes when people vote. The low-cost theory of expressive voting provides an economic explanation for why "morals" may determine referendum outcomes when money and morals conflict.

According to the low-cost theory, people have preferences about the expression of support and about the material outcome of the ballot (Brennan and Lomasky 1993, Brennan and Hamlin 1998). Suppose that the two types of preferences conflict. Consider, for example, a proposal to tax everyone and to donate tax revenues. In this case, voters are supposed to trade-off an expressive utility from the act of voting for the donation against the material costs of voting for the donation. These costs depend on the voting behavior of the rest of the electorate. Since voting decisions are simultaneous, expectations on the resulting approval rate are crucial to this theory. For example, if a voter in a majority vote expects a close outcome there is some chance that his vote will affect the material outcome. In this case, the voter believes to take a high-cost decision. As a consequence, the voter may not approve of the proposal to donate. If, on the other hand, a voter expects a clear defeat of the proposal, his vote will very probably not affect the material outcome. In this case, the voter believes to take a low-cost decision and may approve of the proposal. As Brennan and Lomasky (1993: 45) note, this may lead "each voter ... to vote for the program, even though all (donors) would be better off if the policy did not proceed". In the presence of expressive preferences, therefore, voting may result in aggregate outcomes which nobody preferred. Or, put differently, voting may be an institution in which outcomes are extremely non-robust to the presence of preferences other than material self-interest. 
The example of a referendum to tax everyone and donate the money to a charity is a particularly clear-cut case where expressive preferences and material self-interest conflict and, therefore, serves as a basis for our experiment. ${ }^{1}$ Expressive preferences may reflect various kinds of moral and ideological principles (Eichenberger and Oberholzer-Gee 1998). In fact, such a conflict of "money and morals" is typical for many policy choices. Examples include environmental policy and many types of redistributive issues such as social security, minimum wage laws, or protection for farmers (for evidence on voting on social security issues see Bütler 2000, Breyer and Craig 1997 or van der Heijden et al. 1997). Glazer (1992) discusses evidence on how expressive voting of labor union members may explain the existence of strikes which workers would have preferred to avoid. Schuessler (2000) discusses anthropological foundations of expressive voting and argues that expressive voting may also be important in representative democracy.

This paper theoretically and empirically investigates the role of expectations in voting. On a theoretical level, we show that voters who cast their votes instrumentally are predicted not to condition their voting decision upon their expectations, while an expressive voter does. To empirically investigate expressive voting, we conduct an experimental study. Experimental methods are appropriate to investigate this issue because data on individual expectations and individual voting decisions can be collected under controlled conditions. It may not be possible to obtain such data in the field (see, e.g., Martinez-Vazquez 1981). Experimental techniques allow us to implement ceteris paribus variations in voting rules and approval rate requirements which systematically vary the cost of expressive voting.

Previous attempts to test the low-cost theory experimentally (Carter and Guerette 1992, Fischer 1996) have not analyzed individual expectations. Instead, these studies exogenously vary the probability to cast the decisive vote to donate a certain amount of money to a charity. Cummins et al. (1997) provide an extreme example of a low-cost decision. The authors find that people are significantly more willing to approve of a proposition to donate $\$ 10$ to an environmental project in a hypothetical referendum as compared to a "real" referendum. While these studies have provided interesting insights, they suffer from the shortcoming that they do not analyze the crucial role of individual expectations.

1 The example is taken from Tullock (1971: 388-9). For a broader discussion, see Kirchgässner (1992, 2000: Ch. 5). 
Our experimental tests reveal that expressive voting is common since voting decisions systematically depend on expectations about the outcome of the referendum. However, the low-cost theory clearly fails to account for voting behavior. While the low-cost theory claims that expectations affect the cost side of the voters' calculus, our experimental results suggest that expectations affect the benefit side. In particular, we show that those who expect to affect the outcome of the referendum are not more likely to vote against the proposal. Instead, we find that voters tend to vote for donations if many others are expected to do so. A possible interpretation of this "bandwagon" effect is that the expressive utility of voting for a morally worthy proposal increases with the number of others who also approve.

We proceed as follows: Section 2 discusses differences between instrumental and expressive voting, and explains the crucial role expectations play in this distinction. Section 3 explains the experimental design, and section 4 presents the results. Section 5 provides some concluding remarks.

\section{Expectations and expressive voting}

Economic models of voting assume that voters cast their votes instrumentally. That is, these models assume that voters cast their votes solely to affect the outcome of the referendum. The models of "expressive voting" contest this premise. The starting point of these models is the fact that a voter is non-pivotal most of the time, and, as a consequence, an individual voting decision is inconsequential most of the time. According to Geoffrey Brennan (2001), this implies that an individual voting decision will very much depend on "the benefits and costs that derive from expressing support or opposition to the candidates as an end in itself. [...] The analogy is with cheering at a football match. One cheers to express support for one's team and its athletic exploits; one does not (cannot rationally) believe that one's cheering actually brings about the outcome of the match ...” (225f., emphasis added).

Following a well-established tradition in economic reasoning, the low-cost theory focuses on the cost side of expressive voting - implicitly holding the benefit side constant - to derive testable predictions about voting behavior. According to the low-cost theory, an expressive voter votes according to his material self-interest if the costs of voting for a morally worthy cause are high; but the expressive voter votes morally if the cost of doing so 
are low. ${ }^{2}$ These costs are high if a voter expects to affect the outcome of the referendum with high probability, i.e., if he expects to take a high-cost decision. Therefore, the low-cost theory provides an empirically testable proposition if expectations can be measured. The reason for referring to cost considerations is a methodological one. Explaining changes in behavior by changes in (observable) restrictions is preferred to (not directly observable) changes in preferences (Becker 1976).

Most accounts of the low-cost argument are informal. Below, we provide a simple formal framework, extending work by Brennan (2001). This allows us to derive the hypotheses for the experimental study. In particular, we explain how expressive voting can be distinguished theoretically and empirically from instrumental voting with egoistic preferences and from instrumental voting with altruistic preferences. The assumption of instrumental voting with egoistic preferences is the backbone of the standard economic model of voting. It provides the Null hypothesis of this study against which the low-cost theory of expressive voting is tested. We also discuss instrumental voting with altruistic preferences because altruism provides an obvious alternative explanation for why people approve to be taxed and donate the tax revenues.

\subsection{Expressive voting vs. instrumental voting}

The main distinction between expressive and instrumental accounts of voter behavior based on the role of expectations. Expected voting behavior of others affects expressive voting, but does affect instrumental voting. To illustrate the differences between expressive and instrumental voting, suppose there is a majority vote on a proposal to tax everyone and donate tax revenues. ${ }^{3}$

2 The low-cost theory of expressing support for a morally worthy cause has been suggested to apply to contexts other than voting. For example, Douglass C. North (1990: 22) writes: “...where the price to individuals of being able to express their own values and interests is low, they will loom large in the choices made; but where the price one pays for expressing one's ideology, norms, or preferences is extremely high, they will account much less for human behavior ..."

3 We use this example as a basis for our experiment because it provides a clear-cut example of a conflict between expressive preferences and material self-interest, not because of the literal importance of the issue of voting on charitable donations. However, in some rare cases people in fact vote on charitable donations. The Swiss federal government recently proposed to create a "foundation for solidarity". The endowment of this foundation is supposed to come from selling 1,300 tons of gold from the reserves of the Swiss National Bank. A third of the revenues is supposed to go to the foundation, a third to the member states (Kantons), and a third to social security. The referendum is scheduled for September 22, 2002. At the same time, the Swiss will vote on a competing proposal to use the entire revenues for social security. 
Table 1 illustrates voter $i$ 's costs and benefits in case $i$ approves or disapproves in a majority vote to tax everyone and donate revenues. In this table, $x$ is $i$ 's material payoff in case the proposal is rejected, $y$ is the material payoff in case the proposal is accepted $(x>y)$. We denote by $\alpha \geq 0$ the utility an altruistic voter reaps from donations. Note that $\alpha$ is an instrumental utility since it accrues to voter $i$ exclusively if the tax revenues are actually donated (for evidence on $\alpha$ in an individual donation context see, e.g., Eckel and Grossmann 1996, Hoffman et al. 1996, Bolton and Katok 1998). $\varepsilon \geq 0$ denotes the expressive utility for voter $i$ in case $i$ votes for the morally worthy proposal. Note that since $\varepsilon$ is an expressive utility it accrues to voter $i$ whenever $i$ approves of the proposal, and that this is independent of whether money is actually donated. ${ }^{4}$ While the instrumental payoffs $x, y$ and $\alpha$ depend on the outcome of the referendum, the expressive utility $\varepsilon$ comes directly from expressing support for the morally worthy proposal, in and of itself.

Table 1: Illustration of instrumental and expressive voting in majority voting

\begin{tabular}{|c|c|c|c|}
\hline Voter $i$ votes & $\begin{array}{c}\text { Minority } \\
\text { votes for proposal } \\
\text { (expected with prob. } q)\end{array}$ & Tie & $\begin{array}{c}\text { Majority } \\
\text { votes for proposal } \\
\text { (expected with prob. } r \text { ) }\end{array}$ \\
\hline Yes & $x+\varepsilon$ & $y+\alpha+\varepsilon$ & $y+\alpha+\varepsilon$ \\
\hline No & $x$ & $x$ & $y+\alpha$ \\
\hline
\end{tabular}

We consider a referendum in which all voters cast their votes simultaneously, and in which voter $i$ is uncertain about the outcome of the referendum. We assume that voter $i$ holds expectations about the possible outcomes of the referendum: $q$ is the expected probability that a minority of voters approves, $r$ is the expected probability that a majority of voters approves, and $p$ is the expected probability of a tie. We assume that all probabilities are positive, and that voter $i$ is a risk neutral expected utility maximizer. ${ }^{5}$ The expected utility of voting for the

4 The concept of expressive utility is distinct from the warm-glow utility introduced by Andreoni (1990). A warm-glow utility accrues to an individual donator from the act of donating, independent of whether the donation in fact improves anybody's lot. In contrast, an expressive utility accrues to an individual voter if he votes for the donation. Hence, $\varepsilon$ is independent of whether voting leads to actual donations.

5 In the following, we only discuss optimal voting behavior (i.e., best replies) for given expectations. It appears to be quite difficult to characterize rational expectations voting equilibria in the presence of expressive motives. For an attempt, see Glazer (1992). 
proposal is (see table 1) $\pi$ (yes) $=q(x+\varepsilon)+p(y+\alpha+\varepsilon)+r(y+\alpha+\varepsilon)$, and of voting against the proposal is $\pi(\mathrm{no})=q x+p x+r(y+\alpha)$. Voter $i$ approves if and only if $\pi$ (yes) $>\pi$ (no), i.e., if

$$
\varepsilon>p(x-y-\alpha) .
$$

Consider first an instrumental voter with purely egoistic preferences $(\alpha=0, \varepsilon=0)$. Such a voter always votes no under uncertainty $(p>0)$. The important thing to note is that such a voter votes against the proposal independent of his expectations to be pivotal. Consider now an instrumental voter with altruistic preferences $(\alpha>0, \varepsilon=0)$. Such a voter votes yes if $\alpha>$ $x-y$. Note that an altruist's voting decision too is independent of his expectations about other voters' decisions. ${ }^{6}$

Consider finally a voter with expressive preferences $(\alpha=0, \varepsilon>0)$. Such a voter votes yes if $\varepsilon>p(x-y)$. We assume that the expressive utility is small relative to the utility loss from taxation $(\varepsilon<x-y)$. In this case, whether an expressive voter votes for the morally worthy cause depends on his expectation to be pivotal $p$. In particular, an expressive voter ( $\varepsilon$ $>0$ ) approves if he expects to take a low-cost decision (i.e., $p$ is sufficiently small), while he disapproves if he expects to take a high-cost decision (i.e., $p$ is large).

The discussion above has shown that instrumental voting differs theoretically from expressive voting and that expectations play a crucial role in this distinction. Instrumental voters cast their vote to bring about a certain result. In the presence of uncertainty, the voting behavior of both egoists and altruists does not depend on their expected probability to be pivotal. In contrast, voting decisions of expressive voters depend on their expectations. They tend to vote against the proposal if the expected probability of being pivotal is high (a highcost decision prevails), but tend to vote for the proposal if the expected probability is low (a low-cost decision prevails). This result provides the basis for our experimental design and our test of the low-cost hypothesis.

\footnotetext{
6 One can, of course, think of instrumental preferences implying that voting decisions do depend on expectations. For example, a voter may get an extra utility in the event that he cast the decisive vote, i.e. that his vote "made a difference" (see Duncan 2001 for a discussion).
} 


\section{Experimental Design}

The basic design of the experiment is as follows: Experimental subjects are endowed with some amount of money. Experimental subjects then have to vote on a proposal to donate his or her entire endowment to a charity. In all voting decisions there is an approval rate requirement which will henceforth be called quorum $Q$. If the approval rate a (i.e., the percentage of approving votes) fails to exceed the quorum $Q$, the proposal is rejected. If the approval rate exceeds the quorum, the proposal is accepted. Voters take their decisions according to two different voting rules (treatments $\mathrm{T} 1$ and $\mathrm{T} 2$ ). The two treatments exclusively differ with respect to the consequences in case of an acceptance of the proposal. If the proposal is accepted in T1, all voters donate their endowment. If it is accepted in T2, only those who approved donate their endowment, those who did not approve keep their endowment.

To illustrate the difference between treatments, suppose that the quorum is $Q=50 \%$, and that $a=60 \%$ of the voters approve. In both treatments the proposal is accepted. In T1, whether a particular voter approves or disapproves does not affect his payoff (his endowment is donated anyway). In contrast, in T2 the voter's decision does affect his payoff. If he approves, his endowment will be donated, whereas he will keep his endowment if he disapproves. Given an approval rate above the quorum, an individual faces a low-cost decision in T1, but a high-cost decision in T2. In contrast, given an approval rate below the quorum $(a<Q)$, the individual faces a low-cost decision in both treatments since the voter will keep his endowment irrespective of his individual decision.

The purpose of this treatment variation is to widen the range of approval rates for which high-cost decisions prevail. In T1, the range of approval rates implying a high-cost decision is very small: high-cost decisions prevail for a voter only if he is pivotal. In T2, the range of approval rates implying high-cost decisions is much larger: high-cost decisions prevail for a voter if he is pivotal and if the quorum is exceeded.

To illustrate the difference between the treatments consider again table 1. The only entry of table 1 that has to be changed to analyze treatment $\mathrm{T} 2$ is the lower right corner (i.e., if the proposal is accepted and the voter votes no). Instead of $y+\alpha$, the entry in T2 is simply $x$ 
since voter $i$ keeps his endowment in this case. After this modification (keeping all other assumptions mentioned above), a rational voter votes yes in $\mathrm{T} 2$ if and only if

$$
\varepsilon>(p+r)(x-y-\alpha) \text {. }
$$

A comparison with equation (1) reveals that the calculus of an instrumental and selfish voter $(\alpha=0, \varepsilon=0)$ is unaffected by the treatment variation. Voter $i$ votes no independent of his expectations. The same holds for an instrumental altruistic voter $(\alpha>0, \varepsilon=0)$ who votes yes in $\mathrm{T} 1$ as well as in $\mathrm{T} 2$ if $\alpha>x-y$. The expressive voter, in contrast, takes different decisions in the two treatments. An expressive voter with a particular value of $\varepsilon$ and $p$ may vote yes in $\mathrm{T} 1$ but vote no in $\mathrm{T} 2$. The treatment effect will be the more pronounced the higher his expectation $r$, that is, the higher the expectation to take a high-cost decision.

\subsection{Procedures and parameters}

The experiment was conducted in large lecture halls at the Universities of St. Gallen and Innsbruck. Participants were undergraduate students of all faculties who were recruited a few days before the experiment. Subjects were randomly allocated to Treatment T1 or T2. Each subject was endowed with approx. \$6 (with CHF 10 in St. Gallen, with ATS 100 in Innsbruck), and had to decide whether to keep this endowment or to donate it to a charity. ${ }^{7,8}$

In both $\mathrm{T} 1$ and $\mathrm{T} 2$, each subject had to take decisions for five values of $Q_{j}(j=1, \ldots, 5)$ : $1 \%, 25 \%, 50 \%, 75 \%$, and 99\%. All decisions were taken simultaneously, i.e., subjects had no information about the outcome of either referendum. Each subject $i$ also had to indicate his or her expectation about approval rates $e_{i j}$ for each of the five $Q_{j}$. Subjects knew that they are paid an additional CHF 5 or ATS 50 (approx. \$3) if their expectation was correct. Subjects knew that - after all decisions were taken - one quorum for each group was selected by throwing a fair die. Subjects were told at the beginning of the experiment that only the randomly selected $Q_{j}$ would be relevant for their payoffs.

\footnotetext{
7 The charity was terre des hommes in St. Gallen, and the Red Cross in Innsbruck.

8 We implemented a binary choice (donate CHF 10 or CHF 0) to facilitate the vote-counting during the experiment and to avoid paradoxical voting outcomes with certainty. For example, had we allowed subjects to vote on donations of $\mathrm{CHF} 0,1,2, \ldots, 10$ it would be possible that donations of, for example, CHF 1, 2, 4, 5 were accepted but not the donation of $\mathrm{CHF} 3$.
} 
The variation of $Q_{j}$ allows us to test the low-cost hypothesis at the individual (within subjects) level. By letting each subject take five decisions (i.e., one at each of the five $Q_{j}$ ), we can investigate whether these five decisions of a particular subject are consistent with the lowcost hypothesis of expressive voting. In addition, the variation of $Q_{j}$ allows us to systematically vary the range of expectations implying a high-cost decision in T2. For example, in $\mathrm{T} 2$ with $Q_{l}=1 \%$, all admissible expectations imply a high-cost decision. In contrast, almost all admissible expectations imply a low-cost decision in $Q_{5}=99 \%$. This variation is valuable in testing the low-cost theory on an individual level because it increases the chances that a particular subject has a high-cost expectation at some $Q_{j}$ but a low-cost expectation at another $Q_{k}$. Remember from the discussion of table 1 that instrumental voters should always take the same decision irrespective of expectations. In contrast, expressive voters may take different decisions at the different quora if their expectations differ sufficiently between the quora.

Subjects were given written instructions and had to answer several control questions before the experiment started. The consequences of expecting to be (non-)pivotal were explained to subjects in great detail. To this end, a table similar to table 1 was used (see appendix A). We checked that all subjects answered the control questions correctly and announced this fact publicly. To exclude social pressure or prestige as motives (see Harbaugh 1998), we took great care to guarantee complete anonymity of the decisions. The experiment was conducted according to a double blind procedure, and this fact was credibly communicated. This means that it is common information among subjects that no other subject and no experimenter can identify which subject took which decision. ${ }^{9}$

We designed the instructions and the procedures of the experiment to induce relatively low donations (see also Bohnet and Frey 1999). The reason is that if donations were already very high for high-cost decisions, it would not be possible to observe any increase in approval rates for low-cost decisions. The following procedures were chosen to achieve this end: First, the double blind procedure explained above. Second, we induce the endowment effect (see Kahneman et al. 1991) by physically handing out a bill (either 10 CHF or ATS 100) to each

\footnotetext{
9 Before the experiment started, subjects were randomly assigned to groups (subjects had to draw a card with a participant number). Subjects put their decision sheets in an envelope marked with the participant number. The envelopes were taken to a different room. There, assistants who did not know which person had which participant number calculated approval rates and put the payoffs into the envelopes. The envelopes were then distributed by assistants who had remained in the lecture hall all the time. The overall results of the experiment were announced publicly such that subjects could verify the correctness of their payoffs.
} 
participant at the beginning of the experiment. Third, in the wording of the instructions as well as in our behavior during the experiment we avoided to give subjects the impression that they are somehow morally obliged to donate their endowment to the charity. Rather, we tried to appear as neutral as possible.

\subsection{Predictions for overall and individual voting behavior}

From the discussion in table 1 it is clear that we would like to have a direct measure of the probabilities $p, q$, and $r$. However, because of time restrictions in a class room experiment, we ask subjects to provide a point prediction of the resulting approval rate. Since expectations are crucial to test the low-cost theory, we provide subjects with considerable incentives (approx. \$3) to correctly predict the outcome of the referendum. In the following, we use the symbol $e_{-i j}$ to denote subject $i$ 's point expectation about the approval rate excluding the decision of subject $i$ at the quorum $Q_{j}$.

To be able to relate our empirical measure $e_{-i j}$ to the probabilities, we assume that $q(r)$ is a monotonically decreasing (increasing) function of $e_{-i j}$. That is, a subject who indicates a high expectation $e_{-i j}$ is assumed to assign a low probability to the outcome that the approval rate will be low, and vice versa. According to equation (1), a low-cost decision prevails in $\mathrm{T} 1$ if a voter has a low estimate of being pivotal ( $p$ is low, $q+r$ is large). This is the case if $e_{-i j}$ is "far away" from $Q_{j}$ in T1. According to equation (2) voter $i$ expects to take a low-cost decision in $\mathrm{T} 2$ if the sum of probabilities $p+r$ is small. Given our assumption this is the case if $e_{-i j}$ is "far below" $Q_{j}$ in T2. The symbol $a_{j}\left(e_{-i j}\right)$ indicates the approval rate at quorum $Q_{j}$ among subjects having particular expectations $e_{-i j}$. Therefore, the low-cost hypothesis H(LC) is

H(LC): T1: Approval rates $a_{j}\left(e_{-i j}\right)$ decrease with $e_{-i j}$ for $e_{-i j}<Q_{j}$, and increase with $e_{-i j}$ for $e_{-i j}>Q_{j}$.

T2: Approval rates $a_{j}\left(e_{-i j}\right)$ decrease with $e_{-i j}$.

The hypothesis $\mathrm{H}(\mathrm{LC})$ is tested against the Null hypothesis of instrumental voting, H(IV). This hypothesis simply states that instrumental voters should not make their voting decisions contingent on their expectations in either treatment. As explained in section 2.1, this holds irrespective of whether subjects have egoistic or altruistic preferences.

Figure 1 illustrates the main predictions of the low-cost hypothesis for $Q_{3}=50 \%$. The low-cost theory states that voters tend to approve of the proposition the more certain they are 
not to take a high-cost decision. This is the case the "farther away" expectations $e_{-i j}$ are from $Q_{j}$ in T1, and the "farther below" $e_{-i j}$ from $Q_{j}$ in T2 (see figure 1). The hypothesis H(LC) can be tested within and across treatments. For example, we can test within T2 whether the relation between $e_{-i j}$ and $a_{j}\left(e_{-i j}\right)$ is negative as predicted by $\mathrm{H}(\mathrm{LC})$. To test $\mathrm{H}(\mathrm{LC})$ across treatments we can, for example, test whether $a_{j}\left(e_{-i j}\right)$ is higher in T1 than in T2 for $e_{-i j}>Q_{j}$.

Figure 1: $\quad$ Illustration of the low-cost hypothesis $\mathrm{H}(\mathrm{LC})$ (across subjects, $Q_{j}=Q_{3}$ )
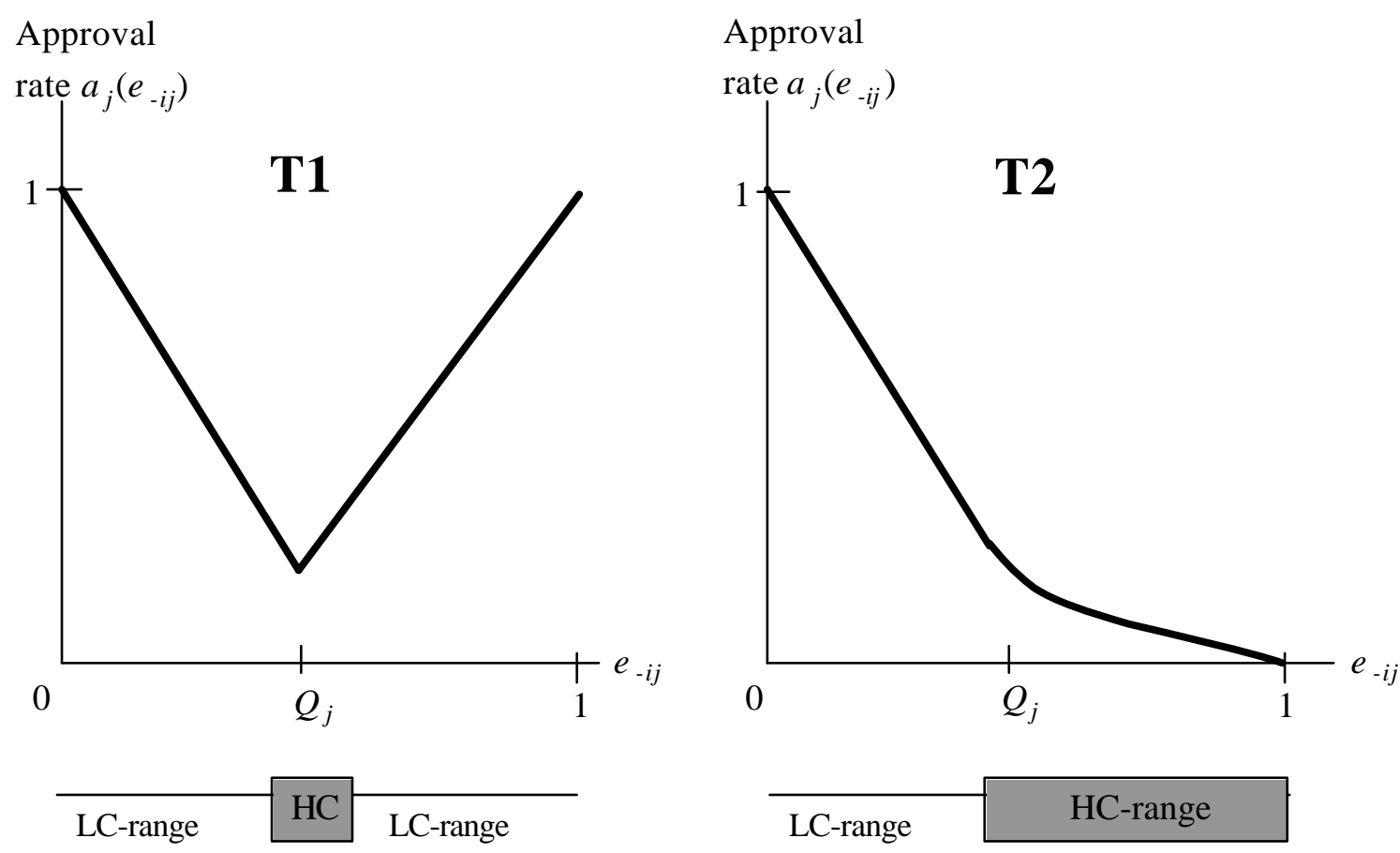

The implications of the low-cost hypothesis can not only be tested for overall voting behavior, but the experimental design also enables us to test the theory at an individual level (across $Q_{j}$ ). The individual-level low-cost hypothesis holds that an expressive voter may "switch" from voting no in $Q_{j}$ to voting yes at some other quorum $Q_{k}$ if he expects to take a low-cost decision in $Q_{k}$. In addition to the monotonicity assumption, we must assume that the distribution of $e_{-i j}$ is approximately constant for a given $i$ across quora $Q_{j}$ to be able to test the individual-level low-cost hypothesis (denoted in lower-case letters): 
H(lc): The voting decisions of voter $i$ are consistent with the low-cost theory if the following conditions hold.

(T1) In case voter $i$ approves at some absolute value $\left|e_{-i j}-Q_{j}\right|$ in $\mathrm{T} 1$, he also approves for higher absolute values $\left|e_{-i k}-Q_{k}\right|$.

(T2) In case voter $i$ approves at some value of $e_{-i j}-Q_{j}$ in T2, he also approves for lower values of $e_{-i k}-Q_{k}$.

The intuition for hypothesis $\mathrm{H}(\mathrm{lc})$ is again that in T1 $p$ decreases the "farther away" $e_{-i j}$ is of $Q_{j}$, and in T2 $(p+r)$ decreases "the farther below" $e_{-i j}$ is of $Q_{j}$.

\section{Results}

In total, 220 subjects participated in the experiment. We report results for the session in St. Gallen (80 subjects) and Innsbruck (140 subjects) jointly. While overall approval rates were somewhat lower in Innsbruck, the qualitative relations between expectations and voting behavior are strikingly similar in the two places. 110 subjects each were randomly assigned to T1 and T2. Subjects on average earned approx. \$10 (including a \$3 show-up fee) within 70 minutes. Section 4.1 investigates overall voting, and section 4.2 investigates individual voting. Section 4.3 analyzes alternative explanations for expressive voting.

\subsection{Overall voting behavior}

Figure 2 shows approval rates for different ranges of expectations at $Q_{3}=50 \%$. For example, in treatment T2 (black bars), 30 subjects expected that between 0 percent and 20 percent of the other voters would approve of the proposal. Of these, 20 percent $(=6 / 30)$ in fact approved. As can be seen from the figure, approval rates increase with expectations in both treatments. In T1 (T2), approval rates increase from 16 percent (20 percent) in the lowest expectation range to 100 percent (100 percent) in the highest expectation range. This contrasts with the Null hypothesis of instrumental voting H(IV) which predicts no relation between expectations and approval rates. According to the graphic illustration of the low-cost hypothesis $\mathrm{H}(\mathrm{LC})$ in figure 1 , we expected the white bars in figure 2 to be U-shaped, and the black bars in figure 2 to be highest at low expectations and to be lowest at high expectations. Both predictions are clearly not met in figure 2. 
Appendix B shows the data for all quora. Surprisingly, the data exhibit a striking regularity. Approval rates increase with expectations at all quora $Q_{j}$. Therefore, both the Null hypothesis $\mathrm{H}(\mathrm{IV})$ and the low-cost hypothesis $\mathrm{H}(\mathrm{LC})$ are not at all reflected in the data.

Figure 2: Approval rates and expectations for all quora $j$ (numbers above bars indicate number of subjects, $N=110$ in each treatment)

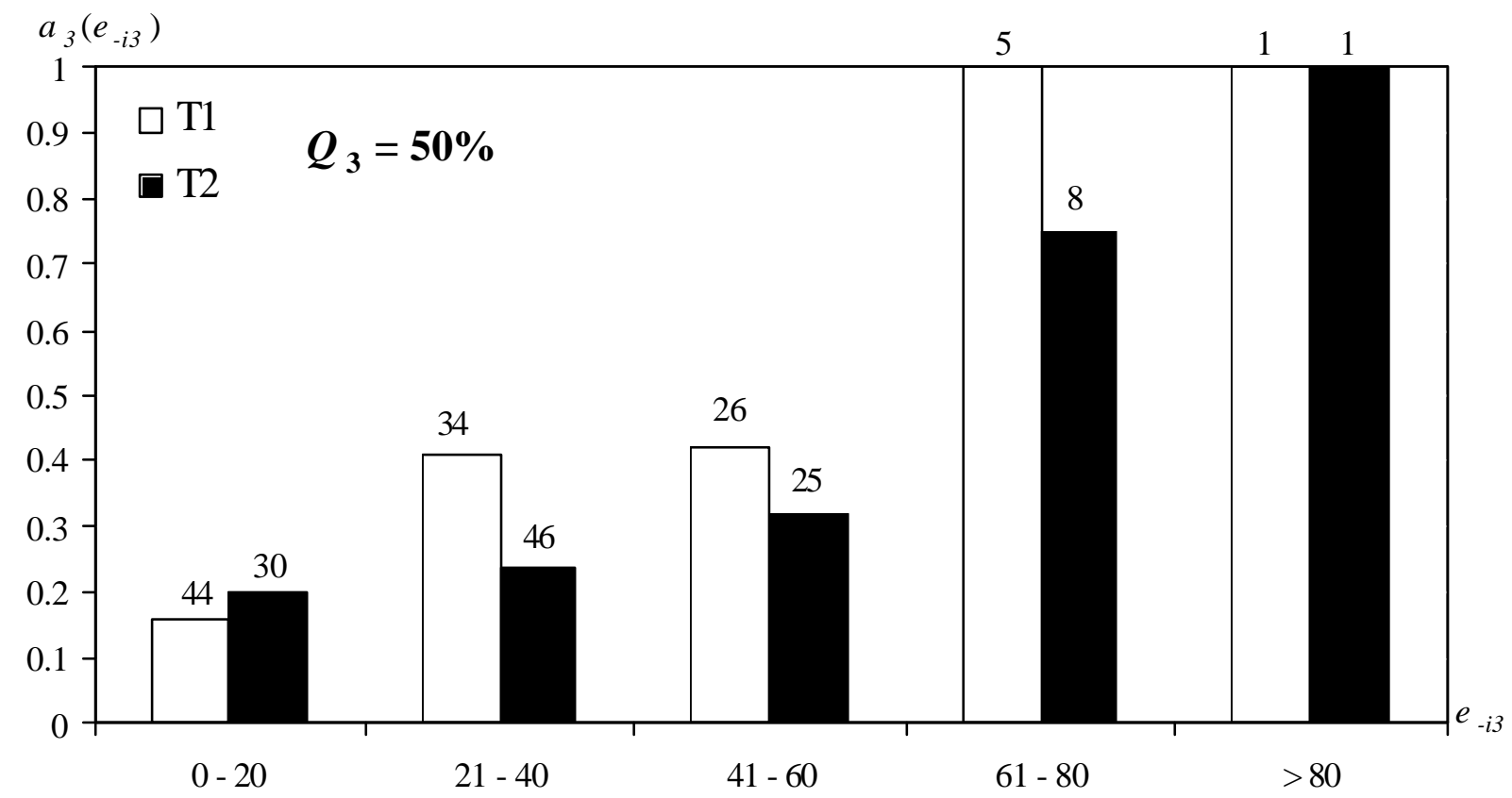

To test the hypotheses $\mathrm{H}(\mathrm{LC})$ and $\mathrm{H}(\mathrm{IV})$ more formally, we calculate Spearman correlation coefficients between $e_{-i j}$ and individual approvals for each $Q_{j}$. Table 2 summarizes the results. According to $\mathrm{H}(\mathrm{IV})$, there should be no significant relation between expectations and approval rates. In contrast, according to $\mathrm{H}(\mathrm{LC})$ there should be a negative correlation in $\mathrm{T} 1$ for observations below pivotality, and a negative correlation in $\mathrm{T} 2$ over the whole range of expectations (see figure 1). The last column of the table reports Spearman correlation coefficients in $\mathrm{T} 1$ for expectations below pivotality. The number of such observations is indicated in parentheses (there are no such observations at $Q_{1}=1 \%$ by definition). Contrary to the predictions of $\mathrm{H}(\mathrm{IV})$ and of $\mathrm{H}(\mathrm{LC})$ in $\mathrm{T} 1$, all four correlation coefficients are significantly positive $(p<0.05)$. Therefore, both $\mathrm{H}(\mathrm{IV})$ and $\mathrm{H}(\mathrm{LC})$ can be rejected in 4 out of 4 cases within T1. In T2, correlations should be negative over the entire range of expectations according to $\mathrm{H}(\mathrm{LC})$. Since all of the correlations for T2 are positive and significant at the 1 percent level, we reject $\mathrm{H}(\mathrm{IV})$ and $\mathrm{H}(\mathrm{LC})$ in 5 out of 5 cases within T2. 
Table 2: $\quad$ Spearman correlation coefficients for each quorum

\begin{tabular}{|l|c|c|c|}
\cline { 2 - 4 } \multicolumn{1}{c|}{} & \multicolumn{2}{|c|}{ All observations } & \multicolumn{1}{c|}{$\begin{array}{c}\text { Observations } \\
\text { below pivotality } \\
\left(e_{-i j}<Q_{j}\right)\end{array}$} \\
\hline & $\mathrm{T} 1$ & $\mathrm{~T} 2$ & $\mathrm{~T} 1$ \\
\hline$Q_{1}=1 \%$ & $0.51 * * *$ & $0.28 * * *$ & $\mathrm{n} . \mathrm{a}$. \\
\hline$Q_{2}=25 \%$ & $0.47 * * *$ & $0.29 * * *$ & $\begin{array}{l}0.32 * * * \\
(n=59)\end{array}$ \\
\hline$Q_{3}=50 \%$ & $0.32 * * *$ & $0.24 * * *$ & $\begin{array}{l}0.25 * * \\
(n=86)\end{array}$ \\
\hline$Q_{4}=75 \%$ & $0.39 * * *$ & $0.29 * * *$ & $\begin{array}{l}0.33 * * * \\
(n=106)\end{array}$ \\
\hline$Q_{5}=99 \%$ & $0.48^{* * * *}$ & $0.50^{* * * *}$ & $\begin{array}{l}0.48^{* * *} \\
(n=110)\end{array}$ \\
\hline
\end{tabular}

$* * *=$ significant at the 1 percent level, $* *=$ significant at the 5 percent level (one-tailed).

We also evaluate the predictive success of the low-cost theory across treatments. According to the low-cost theory, approval rates should be higher in $\mathrm{T} 1$ than in $\mathrm{T} 2$ for expectations above $Q_{j}$. To detect whether there is a treatment effect, we test at each $Q_{j}$ whether $a_{j}(e$. ${ }_{i j}$ ) is significantly different in T1 and T2 for $e_{-i j}>Q_{j}$. In the 4 cases that allow us to conduct a chi-square test (there can be no observations $e_{-i 5}>Q_{5}$ by definition), we find no significant treatment differences at the 10 percent level. Therefore, we reject $\mathrm{H}(\mathrm{LC})$ in 4 out of 4 cases.

In summary, the Null hypothesis of instrumental voting is not successful in predicting overall voting behavior. While this hypothesis claims that there should be no relation between expectations and voting, we find highly significant positive correlations at all quora. More importantly, the low-cost hypothesis is rejected in 11 out of 13 cases (within and across treatments) if we use observations from all subjects.

However, one could argue that using observations from all subjects biases results against the low-cost hypothesis. The reason is heterogeneity of voters. Some voters may be instrumental (purely egoistic or altruistic), some may be expressive voters. As explained in section 2, expressive voters are predicted to make their voting decision contingent upon their expectations. As a consequence, they may vote yes at some quora, but no at other quora if they hold different expectations at different quora. In fact, 46 percent always vote no, 14 
percent of voters always vote yes, and 40 percent of voters vote yes at some quora but vote no at other quora. That is, 60 percent of voters are consistent with instrumental voting while 40 percent of voters are consistent with expressive voting. This is an important result since it indicates that expressive voting is potentially common. ${ }^{10} \mathrm{We}$ will henceforth call the voters who took different decisions at different quora "switchers". We will now investigate whether these switchers voted according to the predictions of the low-cost theory.

Table 3: $\quad$ Spearman correlation coefficients for each quorum, switchers ${ }^{\text {a) }}$ only.

\begin{tabular}{|c|c|c|c|}
\hline & \multicolumn{2}{|c|}{ All observations } & \multirow{2}{*}{$\begin{array}{c}\begin{array}{c}\text { Observations } \\
\text { below pivotality } \\
\left(e_{-i j}<Q_{j}\right)\end{array} \\
\mathrm{T} 1\end{array}$} \\
\hline & $\begin{array}{c}\mathrm{T} 1 \\
(n=48)\end{array}$ & $\begin{array}{c}\mathrm{T} 2 \\
(n=40)\end{array}$ & \\
\hline$Q_{l}=1 \%$ & $0.61 * * *$ & 0.04 & n.a. \\
\hline$Q_{2}=25 \%$ & $0.49 * * *$ & $0.38 * * *$ & $\begin{array}{l}0.39 * * \\
(n=23)\end{array}$ \\
\hline$Q_{3}=50 \%$ & 0.11 & $0.23 *$ & $\begin{array}{l}0.00 \\
(n=37)\end{array}$ \\
\hline$Q_{4}=75 \%$ & $0.35^{* * * *}$ & 0.06 & $\begin{array}{l}0.26^{* *} \\
(n=45)\end{array}$ \\
\hline$Q_{5}=99 \%$ & $0.64 * * *$ & $0.41 * *$ & $\begin{array}{l}0.64 * * * \\
(n=48)\end{array}$ \\
\hline
\end{tabular}

$* * *=$ significant at the 1 percent level, $* *=$ significant at the 5 percent level,

$*$ = significant at the 10 percent level (one-tailed).

a) Switchers are voters who do not take the same decision at each $Q_{j}$.

Table 3 reports the results from repeating the tests of table 2 for switchers only. We find that only considering switchers does not change the overall conclusion. Instead of the negative correlations predicted by $\mathrm{H}(\mathrm{LC})$ for expectations below pivotality in $\mathrm{T} 1$, we find three significantly positive correlations (see rightmost column of table 3). In T2, H(LC) predicts negative correlations. As the middle column of Table 3 shows, however, not one of the correlations is negative. Therefore, the low-cost hypothesis is rejected in 9 out of 9 cases within treatments.

\footnotetext{
${ }^{10}$ Switching per se does not imply expressive voting. Switchers could, for example, just have cast their votes randomly. However, this is not the rule, as is explained below.
} 
Across treatments, the low-cost hypothesis predicts higher approval rates in T1 than in T2. However, we reject this hypothesis in 3 out of 4 cases across treatments (according to a chi-square test, at the 10 percent level of significance). We conclude that even when considering only voters who's behavior is consistent with expressive voting (i.e., the switchers) we must reject the low-cost theory as an explanation of expressive voting.

\subsection{Individual voting decisions}

We now analyze the voting decisions of individual voters (within subjects) across $Q_{j}$. In the following, we will exclusively focus on the behavior of voters who took different decisions at the five $Q_{j}$ ("switchers"). As expected, the percentage of switchers with high-cost expectations at some $Q_{j}$ and low-cost expectations at other $Q_{k}$ is different in the two treatments (this was one of the reasons to implement the treatment variation). We consider voter $i$ to have a high-cost expectation if his point expectation is such that $i$ expects to affect the outcome. According to this definition, 42 percent (= $20 / 48)$ of subjects in T1, and 98 percent $(=39 / 40)$ in T2 hold a high-cost expectation in at least one decision but a low-cost expectation in others. Given these high percentages, the individual data provide a very good basis to test the predictive power of the low-cost theory.

To analyze whether the five decisions of each switcher were all consistent with the lowcost hypothesis $\mathrm{H}(\mathrm{lc})$, we proceed as follows: The five pairs of observations for each of the 88 switchers (48 in T1, and 40 in T2) are ordered from low to high according to the absolute value $\mid e_{-i j}-Q_{j} \mathrm{I}$ in T1 (in T2: $Q_{j}-e_{-i j}$ ). The decisions of switcher $i$ are classified as being consistent with the low-cost theory if a sequence of voting decisions emerges that starts with a disapproval $(n)$ and ends with an approval (y) with only one switch from $n$ to $y$ in between. That is, the following sequences are consistent with the low-cost theory: $n, y, y, y, y ; n, n, y, y, y$; $n, n, n, y, y ; n, n, n, n, y$. Note that there are 30 possible sequences of $n$ and $y$ (for switchers), of which 4 sequences are consistent with $\mathrm{H}(\mathrm{lc})$. In T1 (T2), only 11 (23) switchers exhibited a pattern consistent with low-cost theory. That is, only 39 percent of switchers took decisions consistent with the low-cost theory. Therefore, the evidence suggests that the low-cost theory is not successful in explaining individual voting decisions. 


\subsection{How else can expressive voting be explained?}

The standard economic model of egoistic and instrumental voting provides no satisfactory explanation of overall and individual voting in this experiment. The discussion in section 4.1 has clearly shown that the instrumental voting hypothesis $\mathrm{H}(\mathrm{IV})$ is rejected in all cases within treatments. While this hypothesis predicts no correlation between expectations and approval rates, we find highly significant correlations. At the individual level, only 46 percent of voters are consistent with the assumption of instrumental egoism, and 14 percent are consistent with instrumental altruism.

Two facts stand out that jointly indicate that expressive voting is common. First, we find at the individual level that 40 percent of subjects are "switchers", i.e., they change their voting behavior when they have different expectations about the outcome of the referendum. That this observation is not the result of random voting behavior is suggested by the significant positive correlations between expectations and overall voting behavior. In other words: People tend to vote for the proposal if they expect many others to vote for the proposal. This simple relation between expectations and voting decisions turns out to be surprisingly successful in organizing the data.

Conformity has been suggested as a powerful behavioral motive in social psychology (e.g., Smith and Mackie 2000: Ch. 9). Starting with the seminal work of Asch (1955), an impressive body of evidence collected in the laboratory and the field shows that the tendency to "follow the crowd" is strong and widespread (see Kenrick et al. 1999: 207 for references). For example, based on evidence on what their peers are doing, citizens decide whether to pay their taxes fully (Steenbergen et al. 1992). Reingen (1982) has demonstrated that the "list procedure" can be a highly effective fundraising technique. Researchers went door to door collecting money for a charity, showing residents a list of others in the neighborhood who had already given. The longer the list of neighbors that residents saw, the more likely they were to donate (see Kenrick et al. 1999: 211 for a discussion). The findings from social psychology research have also received support in economics experiments on cooperation. Several studies show that people contribute more public goods if others are expected to contribute more to the public good (Fischbacher et al. 2001, Brandts and Schram 2001, Tyran and Feld 2002).

What is called conformity in social psychology is referred to as a "bandwagon" effect in voting research (see, e.g., Hong and Konrad 1998, Bartels 1985). The (ex-post) bandwagon hypothesis $\mathrm{H}(\mathrm{BW})$ claims a positive relation between expectations and approval rates in both 
treatments. Table 2 shows that this hypothesis can be rejected in none of 10 cases within treatments for all subjects. Across treatments, $\mathrm{H}(\mathrm{BW})$ predicts no differences in approval rates for expectations above the quorum. This cannot be rejected in any of the 4 cases across treatments. At the individual level, the bandwagon hypothesis $\mathrm{H}(\mathrm{bw})$ predicts behavior with a striking precision. Switcher $i$ 's decisions are consistent with $\mathrm{H}(\mathrm{bw})$ if the following condition holds: In case voter $i$ approves at some value $e_{-i j}$, he also approves at higher values of $e_{-i j}$.

To test $\mathrm{H}(\mathrm{bw})$, we order pairs of observations for each switcher from low to high $e_{-i j .}{ }^{11}$ If a sequence from $n, y, y, y, y$ to $n, n, n, n, y$ emerges, we classify the decisions of switcher $i$ as being consistent with $\mathrm{H}(\mathrm{bw})$. Overall, 65 switchers (i.e., $73 \%$ in $\mathrm{T} 1$, and $70 \%$ in $\mathrm{T} 2$ ) vote according to $\mathrm{H}(\mathrm{bw})$. According to the difference measure of predictive success $(m)$ suggested by Selten and Krischker (1983), the bandwagon hypothesis is almost three times as successful as the low-cost theory in predicting voting decisions $[m(\mathrm{bw})=0.61, m(\mathrm{lc})=0.22] .^{12}$ According to a chi-square test, significantly more switchers are consistent with $\mathrm{H}(\mathrm{bw})$ than with $\mathrm{H}(\mathrm{lc})(p<0.01)$.

Table 4 summarizes the results of this study. Clearly, expectations importantly affect individual voting decisions, indicating the importance of expressive voting. However, the low-cost theory is not a convincing explanation for this fact since most people do not vote morally if it is cheap to do so. Instead, people seem to vote morally when they expect many others to do so. Note that the bandwagon effect is consistent with expressive voting if we assume that expectations positively affect the benefits of expressive voting. To illustrate, assume that the expressive utility is not constant but increases with the expected approval rate. Assume for example that voter $i$ reaps in a majority vote the expressive utility $\varepsilon_{0}$ if a minority votes for the proposal, $\varepsilon_{1}$ in case of a tie, and $\varepsilon_{2}$ in case a majority votes for the proposal $\left(\varepsilon_{2}>\varepsilon_{1}>\varepsilon_{0}\right.$, compare table 1$)$. Voter $i$ will then vote for the proposal if and only if

$$
q \varepsilon_{0}+p \varepsilon_{1}+r \varepsilon_{2}>p(x-y-\alpha) .
$$

Equation (3) shows that as probability weights are shifted from $q$ to $r$, an expressive voter may switch from voting no to voting yes (because $\varepsilon_{2}>\varepsilon_{0}$ ). That is, if a voter $i$ believes that many others are going to vote for the proposal (i.e., $r$ is large), $i$ is more inclined to

\footnotetext{
${ }^{11}$ Using exclusively observations from switchers makes the test more restrictive. Note, for example, that the decisions of the 60 percent of stayers are not only consistent with instrumental voting but also with $\mathrm{H}(\mathrm{bw})$.

12 The difference measure is defined as follows: $m=r-a$, where $r$ is the hit rate, and the area is $a=$ (\# of predicted outcomes / \# of possible outcomes).
} 
approve than if $i$ expects few others to approve (i.e., $q$ is large). Note that the same result holds for treatment $\mathrm{T} 2$ since the corresponding condition is

$$
q \varepsilon_{0}+p \varepsilon_{1}+r \varepsilon_{2}>(p+\mathrm{r})(x-y-\alpha)
$$

As suggested by Geoffrey Brennan (2001, see quotation in the first paragraph of section 2), the appropriate analogy for expressive voting may be cheering at a football match. If we accept this analogy, we can interpret the finding of this study as follows. Just as it may be more fun to cheer for a team if others cheer too, it may be more rewarding to vote for a morally worthy cause if others are expected to do so, too.

Table 4: Summary of results

\begin{tabular}{|c|c|c|c|}
\hline & $\begin{array}{c}\text { Low-cost hypothesis } \\
\text { (expectations affect the costs } \\
\text { of expressive voting) }\end{array}$ & $\begin{array}{c}\text { Bandwagon } \\
\text { (expectations affect the benefits } \\
\text { of expressive voting) }\end{array}$ \\
\hline & & H(LC) & H(BW) \\
\hline \multirow{4}{*}{$\begin{array}{l}\text { Overall } \\
\text { voting behavior } \\
\text { (across subjects) }\end{array}$} & $\begin{array}{l}\text { All subjects } \\
\text { Within } Q \text {, } \\
\text { within treatments }\end{array}$ & $\begin{array}{c}\text { Reject } \\
\text { in } 9 \text { out of } 9 \text { cases }\end{array}$ & $\begin{array}{c}\text { Cannot Reject } \\
\text { in } 10 \text { out of } 10 \text { cases }\end{array}$ \\
\hline & $\begin{array}{l}\text { All subjects } \\
\text { Within } Q, \\
\text { across treatments }\end{array}$ & $\begin{array}{c}\text { Reject } \\
\text { in } 4 \text { out of } 4 \text { cases }\end{array}$ & $\begin{array}{c}\text { Cannot Reject } \\
\text { in } 4 \text { out of } 4 \text { cases }\end{array}$ \\
\hline & $\begin{array}{l}\text { Switchers only } \\
\text { Within } Q \text {, } \\
\text { within treatments }\end{array}$ & $\begin{array}{c}\text { Reject } \\
\text { in } 9 \text { out of } 9 \text { cases }\end{array}$ & $\begin{array}{c}\text { Cannot Reject } \\
\text { in } 7 \text { out of } 10 \text { cases }\end{array}$ \\
\hline & $\begin{array}{l}\text { Switchers only } \\
\text { Within } Q, \\
\text { across treatments }\end{array}$ & $\begin{array}{c}\text { Reject } \\
\text { in } 3 \text { out of } 4 \text { cases }\end{array}$ & $\begin{array}{c}\text { Cannot Reject } \\
\text { in } 3 \text { out of } 4 \text { cases }\end{array}$ \\
\hline & & $\mathbf{H}(\mathbf{l c})$ & $\mathbf{H}(\mathbf{b w})$ \\
\hline \multirow[t]{2}{*}{$\begin{array}{l}\text { Individual voting } \\
\text { behavior } \\
(\text { across } Q)\end{array}$} & $\begin{array}{l}\text { Percentage of } \\
\text { switchers consistent }\end{array}$ & $39 \%$ & $74 \%$ \\
\hline & $\begin{array}{l}\text { Difference measure of } \\
\text { predictive success } \\
(\mathrm{m}, \text { Selten and } \\
\text { Krischker 1983) }\end{array}$ & 0.22 & 0.61 \\
\hline
\end{tabular}




\section{Concluding remarks}

When "money and morals" conflict in a proposal, voting behavior cannot be satisfactorily explained by the standard (narrow) economic model of voting. This model assumes that egoistic voters cast their votes instrumentally. For example, Dennis Mueller (1989: 456) noted that “... the narrow self-interested model of voting does not explain well the voting behavior of many individuals." The low-cost theory of expressive voting provides an alternative theory, explaining why moral considerations which are relatively unimportant at the individual level may matter much for aggregate voting outcomes. We have argued that expectations play a crucial role in testing the low-cost hypothesis, and that the methods of experimental economics are particularly apt to perform such a test.

The results of this study suggest that expressive voting is common in a referendum on a proposal to tax everyone and to donate tax revenues since expectations about the approval rate in the referendum are found to strongly affect voting decisions. However, we find that expressive voting should not be explained by referring to the low-cost theory, i.e., by referring to how costly expressing support for "morals" is. Instead, expectations appear to affect the benefits of expressive voting. In this case, expressive voting is consistent with "bandwagon" effects. We now explain why these results are surprising and make some suggestions for further research.

The fact that the low-cost theory fails to account for voting behavior is surprising because our experiment provided conditions favorable to the low-cost theory. For example, the instructions and the control questions very much emphasized the decisiveness of voters and the material consequences of individual voting decisions. In addition, subjects were paid for indicating correct expectations which provided incentives to consider how the rest of the electorate is going to vote. The ceteris paribus variations of the experiment were chosen to induce subjects to hold high-cost expectations at some decisions, but low-cost expectations at other decisions. This variation creates ideal preconditions to test the low-cost hypothesis at an individual level because the low-cost theory predicts that voters with expressive preferences should "switch". That is, they should approve of the proposal in some cases but (depending on expectations) not in others. 
We can only speculate on why the low-cost theory fails to account for voting decisions. For example, most voters in naturally occurring elections may not condition their approval on their expectation of decisiveness. Instead, voters may interpret a voting decision in terms of being asked for their sincere opinion on what should be done. Put differently, most people may not vote strategically in naturally occurring referenda, and they may have brought this "natural" behavior to the laboratory (see also Güth and Weck-Hannemann 1997). While this interpretation may explain the behavior of the 60 percent of subjects who always take the same decision, it fails to explain switching.

We find that expectations and voting decisions are positively related. That is, people are more inclined to approve of the proposal if they expect many others to approve. This "bandwagon" hypothesis is strikingly successful in organizing overall and individual voting behavior. For example, 74 percent of switchers took decisions which were consistent with this simple idea. These results appear to be in line with findings from field studies. A tendency to conform with an expected majority has been found to prevail in questionnaire (e.g., Marsh 1984) and voting studies (see, e.g., Bartels 1985). Again, we can only speculate on why the bandwagon hypothesis is so successful in accounting for voting decisions. A bandwagon is consistent with expressive voting if expectations affect the benefits of expressive voting: Just as cheering for the home team may be more fun if others cheer too, it may be more rewarding to vote for "morals" if others do too.

As is forcefully argued by Timur Kuran (1995), bandwagons may be particularly important when people express their opinions publicly because they are subject to social pressure and reputational effects. As a consequence, Kuran (1995) suggests secret voting as an important institution to mitigate possible negative effects of such bandwagons. It is, therefore, surprising that we find such a strong relation between expectations and voting decisions despite the fact that we exclude reputation and social pressure by design.

This study is the first to analyze the relation of voting decisions and expectations about voting outcomes under controlled conditions. Since we found expressive voting to be common, further research should be aimed at gaining a deeper understanding of how voters form expectations, and how they use these expectations to take their decision. 


\section{References}

Andreoni, J. (1990): Impure Altruism and Donations to Public Goods: A Theory of WarmGlow Giving. Economic Journal 100: 464-77.

Asch, S.E. (1955): Studies of Independence and Conformity: A Minority against a Unanimous Majority. Psychology Monographs 70: 1-70.

Bartels, L.M. (1985): Expectations and Preferences in Presidential Nominating Campaigns. American Political Science Review 79(3): 804-15.

Becker, G.S. (1976): The Economic Approach to Human Behavior. Chicago: University of Chicago Press.

Bohnet, I. and Frey, B.S. (1999): Social Distance and Other-Regarding Behavior in Dictator Games: Comment. American Economic Review 89(1): 335-9.

Bolton, G.E. and Katok, E. (1998): An Experimental Test of the Crowding Out Hypothesis: The Nature of Beneficient Behavior. Journal of Economic Behavior and Organization 37: 315-31.

Brandts, J. and Schram, A. (2001): Cooperation or Noise in Public Goods Experiments: Applying the Contribution Function Approach. Journal of Public Economics 79(2): 399-427.

Brennan, G. (2001): Five Rational Actor Accounts of the Welfare State. Kyklos 54(2/3): 21334.

Brennan, G. and Hamlin, A. (1998): Expressive Voting and Electoral Equilibrium. Public Choice 95(1): 149-75.

Brennan, G. and Lomasky, L. (1993): Democracy and Decision. Cambridge: Cambridge Univ. Press

Breyer, F. and Craig, B. (1997): Voting on Social Security: Evidence from OECD Countries. European Journal of Political Economy 13(4): 705-24.

Bütler, M. (2000): The Political Feasibility of Pension Reform Options: The Case of Switzerland. Journal of Public Economics 75(3): 389-416.

Carter, J. and Guerette, S. (1992): An Experimental Study of Expressive Voting. Public Choice 73: 251-60. 
Cummins, R.G., Eliott, S., Harrison, G.W. and Murphy, J. (1997): Are Hypothetical Referenda Incentive Compatible? Journal of Political Economy 103(3): 609-21.

Davis, D.D. and Holt, C.A. (1993): Experimental Economics. Princeton: Princeton University Press.

Duncan, B. (2001): Supporting a Child vs. Supporting a Children's Organization: A Theory of Codependent Philantropy. Working paper University of Colorado at Denver.

Eckel, C.C. and Grossmann, P.J. (1996): Altruism in Anonymous Dictator Games. Games and Economic Behavior 16(2): 181-91.

Eichenberger, R. and Oberholzer-Gee, F. (1998): Rational Moralists: The Role of Fairness in Democratic Economic Politics. Public Choice 94: 191-210.

Fischbacher, U., Gächter, S. and Fehr, E. (2001): Are People Conditionally Cooperative? Evidence from a Public Goods Experiment. Economics Letters 71: 397-404.

Fischer, A.J. (1996): A Further Experimental Study of Expressive Voting. Public Choice 88: $171-80$.

Glazer, A. (1992): An Expressive Voting Theory of Strikes. Economic Inquiry 30(4): 733-41.

Güth, W. and Weck-Hannemann, H. (1997): Do People Care about Democracy? An Experiment Exploring the Value of Voting Rights. Public Choice 91(1): 27-47.

Harbaugh, W. (1998): What do Donations Buy? A Model of Philantropy Based on Prestige and Warm Glow. Journal of Public Economics 67(2): 269-84.

Hoffman, E., McCabe, K. and Smith, V.L. (1996): Social Distance and Other-Regarding Behavior in Dictator Games. American Economic Review 86(3): 653-60.

Hong, C.S. and Konrad, K.A. (1998): Bandwagon Effects and Two-Party Majority Voting. Journal of Risk and Uncertainty 16(2): 165-72.

Kahneman, D. and Knetsch, J.L. and Thaler, R.H. (1991): The Endowment Effect, Loss Aversion, and Status Quo Bias: Anomalies. Journal of Economic Perspectives 5(1): 193-206.

Kenrick, D.T., Neuberg, S.L. and Cialdini, R.B. (1999): Social Psychology. Boston: Allyn and Bacon.

Kirchgässner, G. (1992): Towards a Theory of Low-Cost Decisions. European Journal of Political Economy 8: 305-20. 
Kirchgässner, G. (2000): Homo oeconomicus. 2nd ed. Tübingen: Mohr Siebeck.

Kuran, T. (1995): Private Truths, Public Lies: The Social Consequences of Preference Falsification. Cambridge: Harvard University Press.

Marsh, C. (1984): Back on the Bandwagon: The Effect of Opinion Polls on Public Opinion. British Journal of Political Science 15: 51-74.

Martinez-Vazquez, J. (1981): Selfishness versus Public 'Regardingness' in Voting Behavior. Journal of Public Economics 15: 349-61.

Mueller, D.C. (1989): Public Choice II. Cambridge: Cambridge University Press.

North, D.C. (1990): Institutions, Institutional Change, and Economic Performance. Cambridge: Cambridge University Press.

Reingen, P.H. (1982): Test of List Procedure for Inducing Compliance with a Request to Donate Money. Journal of Applied Psychology 67: 110-8.

Schuessler, A.A. (2000): Expressive Voting. Rationality and Society 12(1): 87-119.

Selten, R. and Krischker, W. (1983): Comparison of Two Theories for Characteristic Function Experiments. In: R. Tietz (ed.): Aspiration Levels in Bargaining and Economic Decision Making. Lecture Notes in Economics and Mathematical Systems 213. Berlin: Springer: 259-64.

Smith, E.R. and Mackie, D.M. (2000): Social Psychology. $2^{\text {nd }}$ ed. Philadelphia: Psychology Press.

Steenbergen, M.R., McGraw, K.M. and Scholz, J.T. (1992): Adaptation to the 1986 Tax Reform Act. In: J. Slemrod (ed.): Why people pay Taxes. Ann Arbor: University of Michigan Press: 21-45.

Stigler, G.J. (1981): Economics or Ethics? In: S.M. McMurrin (ed.): Tanner Lectures on Human Values. Cambridge: Cambridge University Press: 143-91.

Tullock, G. (1971): The Charity of the Uncharitable. Economic Inquiry 9: 379-92.

Tyran, J.-R. and Feld, L.P. (2002): Why People Obey the Law. Experimental Evidence from the Provision of Public Goods. CESIfo working paper 651(2).

van der Heijden, E.C.M., Nelissen, J.H.M. and Verbon, H.A.A. (1997): Altruism and Fairness in a Public Pension System. Journal of Economic Behavior and Organization 32: 505-18. 


\section{Appendix A: Instructions}

(Original instructions were in German. Instructions below refer to T1. We indicate with [T2: ..] how instructions for T2 differed from those for T1.) Instructions below were used in St. Gallen. In Innsbruck, ATS 50 and ATS 100 were paid instead of CHF 5 and CHF 10.

\section{General instructions}

You are participating in an economic experiment which is financed by the Zaugg foundation for basic science. The purpose of this experiment is to analyze voting behavior. You have the opportunity to earn money in this experiment. You will be paid CHF 5 for participation. These CHF 5 (which are paid independently of the outcome of the experiment) as well as all other money earned during the experiment will immediately be paid to you at the end of the experiment in cash.

You are not allowed to communicate with other participants during the experiment. If you have any questions, please ask us. We will gladly answer your questions in private. It is very important that you follow this rule. Otherwise the results of this experiment will be worthless from a scientific perspective.

Here is a short description of the experiment. Detailed instructions follow below.

All participants receive CHF 10. Please check now that your envelope contains CHF 10. The participants are going to decide how these CHF 10 are going to be used. Two outcomes are possible:

1) Your CHF 10 will be donated to a charity. ${ }^{13}$

2) You keep your CHF 10 at your free disposition.

Whether your CHF 10 will be donated may not only depend on your decision but also on the decisions of other participants.

The following pages explain the details of the experiment.

\section{Detailed informations for group 1}

Each participant is a member of a group. You are in a group with 29 other people in this room. Your group is going to decide about the allocation of the money you received. Your group consists of 30 members. No participant knows which persons are in which group. All decisions are perfectly anonymous. That is, neither other participants, nor the organizers of the experiment will be able to know who took which decision.

The other groups in this room take their decisions according to rules which may differ from the rules which are valid for your group. The decisions in other groups are irrelevant for the decisions in your group.

\footnotetext{
13 The charity is the organization "terre des hommes". This charity helps children in Africa suffering want. [Innsbruck: Red Cross]. The organizer of the experiment, Dr. Tyran, personally guarantees that the entire amount donated is transferred to this charity immediately after the experiment. A copy of the receipt will be published at the black board in the main entrance. The original receipt can be checked at the office of Dr. Tyran (Bodanstr. 1, $1^{\text {st }}$ floor) [Innsbruck: Dr. Sausgruber, Main building, $4^{\text {th }}$ floor].
} 
Your group may accept or reject the following proposal:

\section{Proposal:}

The CHF 10 of each participant [T2: of those who approve] will be donated to the charity described above.

If the proposal is rejected, the CHF 10 will remain at the free disposition of each participant.

\section{Voting rules}

Whether your CHF 10 will be donated or not depends on the approval rate, i.e., the decisions of the voters.

Each voter has to decide for each of the "quora" explained below whether he approves (votes YES) or disapproves (votes NO). The expression "quorum" (plural: quora) refers to the percentage of YES-votes which has to be exceeded for the proposal to be accepted. For example, if the quorum is $\mathrm{x}=50 \%$, the proposal is accepted if more than $50 \%$ of the voters vote YES. Abstentions are not possible.

To repeat: The propsal is accepted, if the quorum is exceeded, i.e., if more than $\mathrm{x} \%$ of the voters vote YES. In this case, the CHF 10 of all voters [T2: of those who approve] will be donated to the charity.

The proposal is rejected if the approval rate does not exceed the quorum, i.e., if at most $\mathrm{x} \%$ of all voters vote YES. In this case the CHF 10 remain at the free disposition of each participant.

In this experiment only one of 5 possible quora $(x=1 \%, 25 \%, 50 \%, 75 \%, 99 \%)$ will be relevant for your payment at the end of the experiment. Which of the quora will be relevant will be randomly determined after all voters have taken their decisions.

Example: The following table shows the possible results of the ballot for a quorum of $x=$ $25 \%$ in your group (in total 30 voters). Therefore, one vote has a weight of $3.3 \%$ $(=100 \%$ / 30 voters). 7 YES-votes correspond to an approval rate of $23.3 \%$. Please consult the separate table to see how a particular number of YES-votes translates into approval rates.

\begin{tabular}{|c|c|c|c|}
\hline & \multicolumn{3}{|c|}{ Of all other voters in your group vote (without your vote): } \\
\hline You vote: & $\begin{array}{l}\text { Less than } 7 \\
\text { YES } \\
\text { (i.e., > } 22 \mathrm{NO} \text { ) }\end{array}$ & $\begin{array}{c}\text { Exactly } 7 \\
\text { YES } \\
\text { (i.e., }=22 \mathrm{NO} \text { ) }\end{array}$ & $\begin{array}{l}\text { More than } 7 \\
\text { YES } \\
\text { (d.h. }<22 \mathrm{NO} \text { ) }\end{array}$ \\
\hline YES & $\begin{array}{l}\text { You and all other voters } \\
\text { keep the CHF } 10\end{array}$ & $\begin{array}{l}\text { You and all other voters } \\
\text { donate CHF } 10 \\
\text { [T2: You and all those } \\
\text { who approve] }\end{array}$ & $\begin{array}{l}\text { You and all other voters donate } \\
\text { CHF } 10 \\
\text { [T2: You and all those who } \\
\text { approve donate CHF 10] }\end{array}$ \\
\hline NO & $\begin{array}{l}\text { You and all other voters } \\
\text { keep the CHF } 10\end{array}$ & $\begin{array}{l}\text { You and all other voters } \\
\text { keep the CHF } 10\end{array}$ & $\begin{array}{l}\text { You and all other voters } \\
\text { donate CHF } 10 \\
\text { [T2: You and all those who } \\
\text { disapprove keep the CHF 10] }\end{array}$ \\
\hline
\end{tabular}




\section{What you have to do}

\section{Indication of your expectation}

Please indicate the approval rate you expect for each of the 5 possible quora on the voting form. You have the opportunity to earn additional money if you correctly predict the approval rate. You will earn an additional CHF 5 if your expectation at the quorum which will be selected at random is within a range of $\pm 3 \%$ with respect to the actual approval rate. (In this case, you will receive this money no matter what the result of the vote is).

\section{Your decision}

Take your decision for each of the 5 possible quora (YES or NO).

Use the voting form to indicate your expectation and to take your decision. Here is a specimen of what this voting form looks like. [Not reproduced]

\section{Procedures of the vote}

The vote only starts after all participants have correctly answered the control questions. These control questions are to be found at the end of the instructions. Please do not start with filling out the voting form before we ask you to do so.

1. Put the voting form into the envelope after you have filled out the voting form. Attach the CHF 10-bill visibly (use the paper clip) to the envelope.

2. All envelopes are collected.

3. The quorum which is relevant for the vote and, as a consequence, for your payment is publicly and randomly determined (by throwing a die). Each quorum has the same chance to be selected. To repeat: only one of your decisions will be relevant for your payment.

4. The result of the vote is determined in a different room. The people that count the votes do not know and have no possibility to know which participant has which participant number. This procedure guarantees that your decisions are perfectly anonymous.

5. You will complete a questionnaire while the result of the vote is being determined. This questionnaire, too, is anonymous.

6. The result of the vote for each group is publicly announced. You will receive a sealed envelope. This envelope in any case contains the CHF 5 which you receive for your participation in the experiment. How much additional money the envelope contains depends on the result of the vote and the precision of your prediction. Depending on the result of the vote, the envelope contains:

1. No additional money, if the quorum was exceeded [T2: and you approved];

2. An additional CHF 10, if the quorum was not exceeded [T2: or if the quorum was exceeded and you disapproved]

The envelope contains an additional CHF 5, if you precisely ( $\pm 3 \%$ ) predict the approval rate.

Please do not open the envelope until you left the auditory and please do not tell any participant how much you earned. 


\section{Summary}

A vote will decide whether your CHF 10 are donated to a charity. Your group has 30 voters.

For each of the 5 quora, you have to indicate the proportion of Yes-votes you expect and which decision you take. Only one of these 5 quora will be relevant for your payment at the end of the experiment. Which one of your five decisions will be relevant will be determined after all voters have taken their decisions. Each of the 5 quora is equally probable.

The CHF 10 of all participants [T2: of those who approved] are donated, if the quorum is exceeded.

The CHF 10 are at the free disposition of each voter, if the quorum is not exceeded.

Your decisions are guaranteed to remain completely anonymous.

You will be paid an additional CHF 5 if you predict the approval rate correctly, i.e., if the difference between your expectation at the randomly determined quorum and the actual approval rate is not more than $\pm 3 \%$,

\section{Control questions Group 1}

Please answer all questions (Yes/No). If you have any problems in answering these questions please refer to one of the organizers. In the following, $\mathrm{x} \%$ is the quorum, that has to be exceeded, if the proposal is to be accepted. Your group consists of 30 voters. As a consequence, one voter has a weight of 3.3\%. (Further correspondences between the number of voters and voting weights are to be found in the separate table.)

1. Suppose that $\mathrm{x}=50 \%$ and in your group (excluding yourself) 14 voters $(=46.7 \%)$ approve of the proposal. Will your CHF 10 be donated if you vote Yes?

Will your CHF 10 be donated if you vote No?

2. Suppose that $\mathrm{x}=50 \%$ and in your group (excluding yourself) 15 voters $(=50 \%)$ approve of the proposal. Will your CHF 10 be donated if you vote Yes?

Will your CHF 10 be donated if you vote No?

3 . Suppose that $\mathrm{x}=50 \%$ and in your group (excluding yourself) 16 voters $(=53.3 \%)$ approve of the proposal. Will your CHF 10 be donated if you vote Yes?

Will your CHF 10 be donated if you vote No?

4. Suppose that $\mathrm{x}=75 \%$ and in your group (excluding yourself) 21 voters $(=70 \%)$ approve of the proposal. Will your CHF 10 be donated if you vote Yes?

Will your CHF 10 be donated if you vote No?

5. Suppose that $x=75 \%$ and in your group (excluding yourself) 22 voters $(=73.3 \%)$ approve of the proposal. Will your CHF 10 be donated if you vote Yes?

Will your CHF 10 be donated if you vote No?

6 . Suppose that $\mathrm{x}=1 \%$ and in your group (excluding yourself) 0 voters $(=0 \%)$ approve of the proposal. Will your CHF 10 be donated if you vote Yes?

Will your CHF 10 be donated if you vote No?

7. Suppose that $\mathrm{x}=99 \%$ and in your group (excluding yourself) 29 voters $(=96.7 \%)$ approve of the proposal. Will your CHF 10 be donated if you vote Yes?

Will your CHF 10 be donated if you vote No? 
8. Suppose that $\mathrm{x}=50 \%$ will be randomly determined after the vote. Suppose you indictate an expectation of $42 \%$.

a) Suppose the actual approval rate is $46.7 \%$.

Will you be paid additional CHF 5 at the end of the experiment?

b) Suppose the actual approval rate is $40 \%$.

Will you be paid additional CHF 5 at the end of the experiment?

(Subject No. 1.01-1.31)

\section{Voting form}

Do you approve of the following proposal?

\section{Proposal:}

The CHF 10 of all voters [T2: of those who approve] are donated to the charity described above.

Please indicate for each of the following quora, your expectation about the proportion of Yesvotes as well as your decision. You have to fill out all 10 squares of the voting form. Abstentions are not possible.

\begin{tabular}{|c|c|c|c|c|c|}
\hline & \multicolumn{5}{|c|}{ Quorum $(=x \%)$} \\
\hline & $1 \%$ & $25 \%$ & $50 \%$ & $75 \%$ & $99 \%$ \\
\hline $\begin{array}{c}\text { Your } \\
\text { Expectatio } \\
\text { (\% age of Yes- } \\
\text { integer nu } \\
\text { please }) \\
\end{array}$ & & & & & \\
\hline $\begin{array}{c}\begin{array}{c}\text { Your } \\
\text { Decision }\end{array} \\
\text { (YES or NO) }\end{array}$ & & & & & \\
\hline
\end{tabular}

Please put the voting form into the envelope when you have taken your decisions. Please attach the CHF 10 on the outside of the envelope (use the paper clip). 


\section{Appendix B}

The following figures show approval rates $a_{j}$ for particular expectation ranges $e_{-i j}$ for the quora $j=1,2,4,5$ (Numbers above bars indicate number of subjects, $N=110$ in each treatment). Data for $j=3$ are to be found in section 4.1 (figure 2).
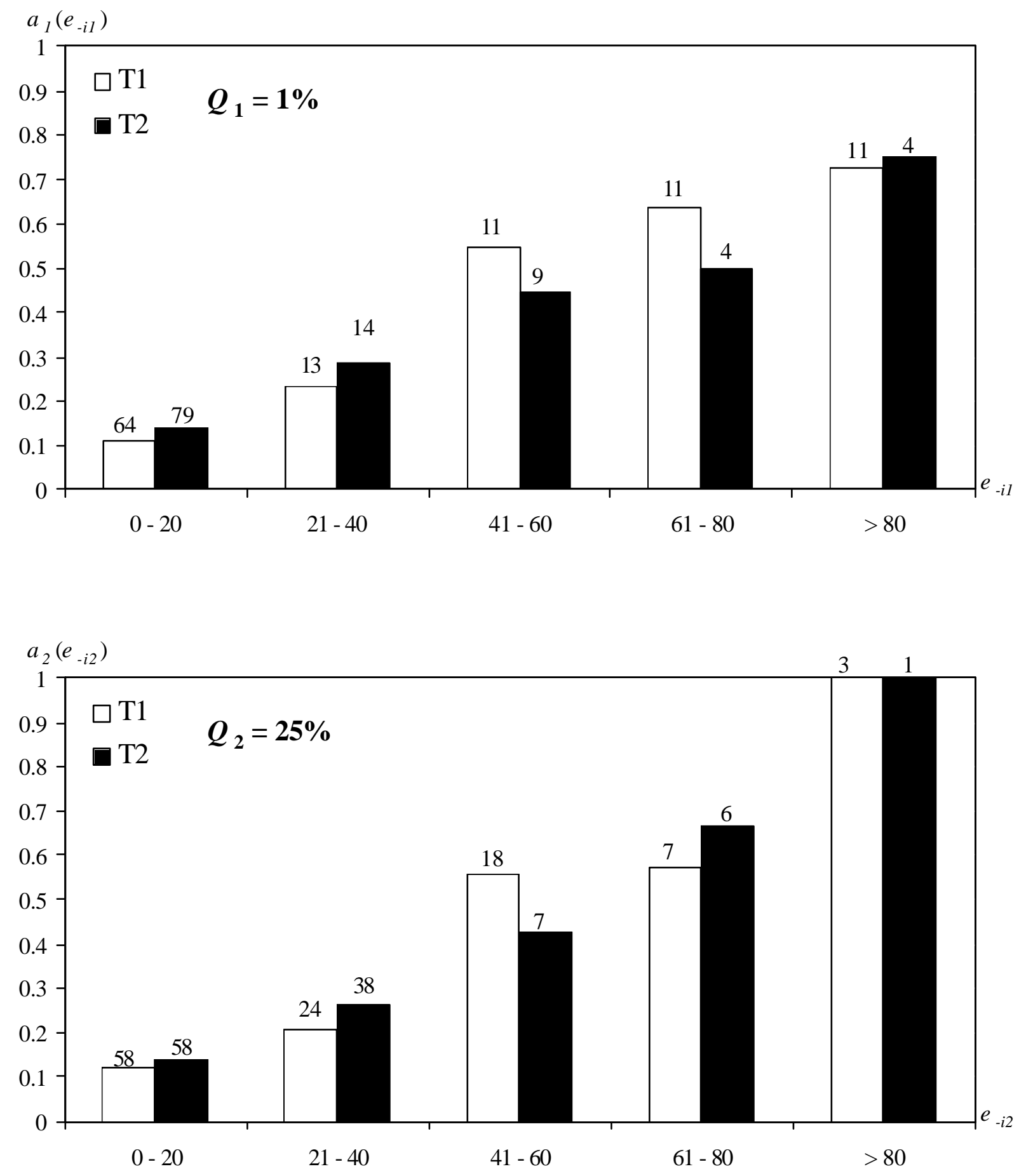
(continued)
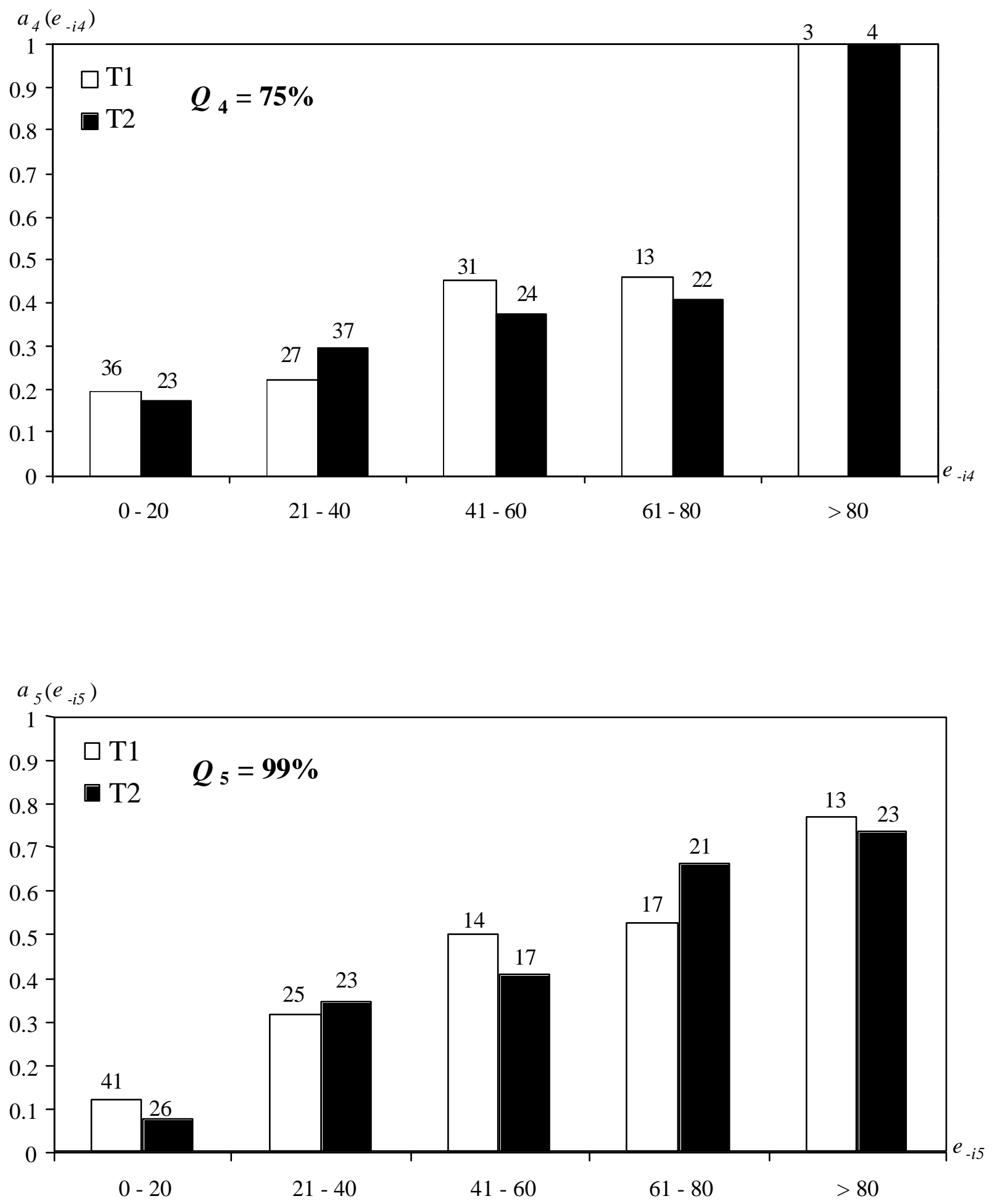